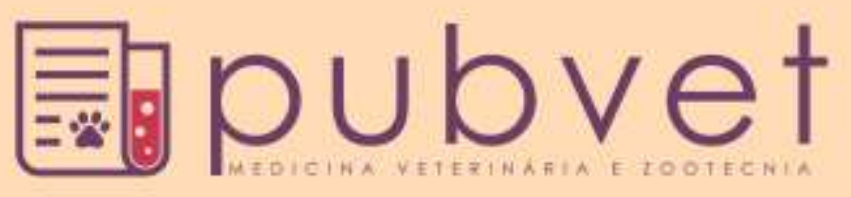

HTTP://DX.DOI.ORG/10.22256/PUBVET.V11N3.224-228

\title{
Boas práticas de fabricação em agroindústria familiar de processamento de guariroba
}

\author{
Vera Lúcia Maria de Brito ${ }^{1}$, Karyne Oliveira Coelho ${ }^{2,3 *}$, Thalita Silva Freitas ${ }^{4}$, Lorrayne \\ Lays Ferreira Leite ${ }^{4}$, Clarice Backes ${ }^{2,3}$, Fernanda Rodrigues Taveira Rocha ${ }^{2}$.
}

${ }^{\text {I} P o ́ s-g r a d u a n d a ~ e m ~ G e s t a ̃ o ~ d a ~ Q u a l i d a d e ~ e ~ S e g u r a n c ̧ a ~ d e ~ A l i m e n t o s ~ p e l a ~ U n i v e r s i d a d e ~ E s t a d u a l ~ d e ~ G o i a ́ s ~(U E G) ~-~ S a ̃ o ~ L u i ́ s ~}$ de Montes Belos, Goiás, Brasil.E-mail:veradamata@bol.com.br

${ }^{2}$ Professora Doutora da Universidade Estadual de Goiás (UEG) - São Luís de Montes Belos, Goiás, Brasil. E-mail: karyne.coelho@ueg.br; clarice.backes@ueg.br; fernanda.rocha@ueg.br

${ }^{3}$ Bolsista de Incentivo ao Pesquisador da Universidade Estadual de Goiás (BIP/UEG)

${ }^{4}$ Mestranda em Desenvolvimento Rural Sustentável da Universidade Estadual de Goiás (UEG) - São Luís de Montes Belos, Goiás, Brasil.E-mail: lorraynnelays@hotmail.com; thalita-freitas@hotmail.com

* Autor para correspondência

\begin{abstract}
RESUMO. Objetivou-se avaliar a aplicação das boas práticas de fabricação (BPF) em uma agroindústria familiar de processamento de guariroba na cidade de Aurilândia/Goiás. O trabalho foi realizado em uma pequena unidade agroindustrial de processamento de Guariroba, na zona rural de Aurilândia, Goiás, durante o período de setembro a dezembro de 2015. Foi utilizada uma adequação da lista de verificação proposta pela Resolução da Diretoria Colegiada 275. A taxa de adequação do estabelecimento foi de $88 \%$. A agroindústria de processamento de guariroba analisada apresentou condições positivas para realizar o processamento de alimentos para humanos. Conclui-se que a implantação das BPFs nesta empresa foi executada com sucesso, atingindo os objetivos propostos, observando o quanto é complexa a implantação na íntegra das BPFs e que há necessidade de melhorias constantes, utilizando-se as ferramentas da qualidade.
\end{abstract}

Palavras chave: Agricultura familiar, alimento, controle, gestão, qualidade

\section{Good manufacturing practices in family agroindustry processing of heart of palm guariroba}

\begin{abstract}
This study aimed to discuss the importance of the implementation of good manufacturing practices in a small family agribusiness guariroba processing in the city of Aurilândia/Goiás. The study was conducted in a small agroindustrial unit Guariroba processing in rural Aurilândia in the state of Goiás, during the period from September 2015 an adaptation of the checklist was used (check list attached). From the completion of the checklist, the opportunities for improvement were identified. During the period evaluated in the study, the rate of adaptation of property estimated at $88 \%$, number that can be classified as "good". The analyzed guariroba processing agro showed positive conditions for carrying out the processing of food for humans. It was concluded that the implementation of GMPs in this company was successful, reaching the goals, noting how complex the implementation of GMPs in full and that there is need for constant improvement, using quality tools.
\end{abstract}

Keywords: Control, family agriculture, food, management, quality 


\title{
Buenas prácticas de fabricación en la agroindustria familiar de procesamiento de palmito guariroba
}

\begin{abstract}
RESUMEN: Este estudio tuvo como objetivo evaluar la implementación de buenas prácticas de fabricación (BPF) en una agroindustria familiar de procesamiento de guariroba en la ciudad de Aurilândia / Goias. El estudio se realizó en una pequeña unidad de procesamiento agroindustrial de guariroba en la zona rural de Aurilândia, Goiás, durante el período de septiembre-diciembre, 2015. Fue utilizada una adaptación de la lista de verificación propuesta por la Resolución del cuerpo colegiado 275. La tasa de adecuación del establecimiento fue del $88 \%$. La agroindustria de procesamiento de guariroba analizada mostró condiciones positivas para llevar a cabo el procesamiento de alimentos para consumo humano. Se concluyó que la implementación de las BPM en esta empresa fue ejecutada con éxito, alcanzando los objetivos propuestos, teniendo en cuenta la complejidad de la implementación de las BPM en su totalidad y que existe la necesidad de mejorías constantes, utilizando las herramientas de calidad.
\end{abstract}

Palabras clave: agricultura familiar, alimento, control de calidad, gestión, calidad

\section{Introdução}

Observa-se que apenas a comercialização de produtos in natura por pequenos produtores não tem sido rentável suficiente para o sustento da família rural, por isso, tem-se a importância de agregar valor à produção de alimentos pela oferta de um produto não processado, diferenciado, ou usando vantagens da prática do processamento agroindustrial (Cruz, 2007).

França et al. (2009) e Kamimura et al. (2010) destacaram que o modelo agrícola brasileiro tem a agricultura familiar como responsável por $70 \%$ da produção de alimentos no país. Por esta razão, são importantes aliados no desenvolvimento local sustentável, na geração de renda, emprego, redução do êxodo rural e na promoção da segurança alimentar.

No estado de Goiás, destacam-se algumas unidades processadoras de frutos do cerrado, dentre os quais as que processam a guariroba. A guariroba Syagrus oleracea é uma palmeira nativa do Cerrado. Segundo Andrade et al. (1996) possui ampla distribuição geográfica no Brasil. O palmito obtido apresenta sabor amargo, boa aceitabilidade e demonstra potencial para expansão do mercado consumidor (Jaime et al., 2007). O processamento em forma de doces e do produto minimamente processado tem agregado valor agregado à Guariroba.

A industrialização de matérias-primas agropecuárias é uma das alternativas para o pequeno produtor rural, em virtude da agregação de valor. As tecnologias de transformação dessas matérias-primas são conhecidas por parte da maioria dos agricultores familiares, devido às informações transmitidas de pais para filhos. Entretanto, os conhecimentos de como e por que produzir com qualidade e segurança assegurada é quase sempre um mito entre esses agricultores (Brasil, 2006). Portanto, torna-se essencial investir em ferramentas de qualidade (Silva and Correia, 2011, Anacleto and Paladini, 2014).

O presente trabalho foi proposto com o intuito de avaliar a aplicação das BPF em uma agroindústria familiar, de processamento de guariroba, no município de Aurilândia/Goiás.

\section{Material e Métodos}

O trabalho foi realizado em uma pequena unidade agroindustrial de processamento de Guariroba, na zona rural de Aurilândia, no estado de Goiás, durante o período de setembro a dezembro de 2015. A indústria analisada possui em seu quadro quatro funcionários e produz doce e a guariroba minimamente processada. Em um primeiro momento foi realizado o diagnóstico situacional da empresa, de maneira detalhada, sendo analisada a estrutura, funcionamento da produção, manipulação de produto, escolha de matérias-primas, equipamentos utilizados e funcionários. Após o diagnóstico, fez-se o acompanhamento da rotina de recebimento de matérias-primas, produção e expedição. Foi realizado o acompanhamento das atividades de produção, como forma de avaliar as adequações necessárias no que se refere à BPF.

Depois do acompanhamento do processo, foi utilizada uma adequação da lista de verificação proposta pela RDC 275 , de 2002 da ANVISA (Brasil, 2002). O check list foi elaborado, considerando cinco aspectos, edificações e 
instalações; equipamentos, móveis e utensílios; manipuladores; produção e transporte de alimento e documentação. As visitas foram acompanhadas por um responsável pela agroindústria; que mostrava as dependências do estabelecimento e fazia um breve relato do processo produtivo. Em seguida preencheu-se o check list, onde cada item foi marcado considerando: Conforme (C), Não Conforme (NC) ou Dispensa de avaliação (D), de acordo com o aspecto visual do componente observado e/ou pela entrevista com o proprietário.

A partir da realização do check list, foram verificadas as oportunidades de melhorias. Para o estabelecimento considerado: Bom (Grupo I), é necessário que este atinja uma porcentagem de adequação entre 76 e $100 \%$ no check-list; para ser classificado como Regular (Grupo II), a adequação deve estar entre 51 e $75 \%$ e, para ser classificação com Ruim (Grupo III), um estabelecimento precisa apresentar entre 0 e $50 \%$ de adequação. A porcentagem de adequação foi calculada pela multiplicação do número de itens de acordo por 100, dividindo-se pelo valor pelo número de itens avaliados.

\section{Resultados e Discussão}

Durante o período avaliado, a taxa de adequação do estabelecimento foi de $88 \%$, número classificado como "Bom". Observam-se na Tabela 1 os resultados dos aspectos avaliados pelo check list e sua respectiva classificação.

Observa-se que o pior desempenho em termos percentuais, foi em relação à produção/ manipulação/venda, sendo o quesito "fluxo adequado (fluxo linear de um só sentido, evitando a contaminação cruzada, locais de prépreparo/área suja, isolados; manipulação mínima e higiênica)" e o quesito "análises laboratoriais com frequência" os responsáveis pela não conformidade nesse item. O fluxo de operações é realizado em condições higiênicas desde a chegada da matéria prima, durante o processo de produção e até a obtenção do produto final; porém estas etapas na indústria avaliada são realizadas em uma mesma sala, dentro de um fluxograma com mais de um sentido. A contaminação cruzada deve ser evitada por meio de instalações e fluxo de operações adequadas. As análises laboratoriais devem ser realizadas com frequência, contribuindo na redução do impacto à saúde pública, prevenindo doenças e possibilitando a retirados do mercado produtos inadequados à comercialização.

Em segundo lugar quanto a apresentação de não conformidades, destaca-se a "edificações e instalações", sendo que os problemas identificados, relacionavam-se: "localização adequada: área de focos de insalubridade (ausência de lixos, objetos em desuso, animais, insetos e roedores, na área interna e vizinhança)", "acesso adequado (direto e independente, não comum a outros usos)" e "ventilação". Neste sentido, indica-se concluir o projeto de criação de pequenos animais e retirar o criatório que se encontra nas proximidades da agroindústria de processamento de guariroba, instalar uma via de acesso exclusivo para agroindústria e ampliar a potência da ventilação dentro da unidade.

Tabela 1. Adequação das BPF pela lista de verificação adaptada da RDC 275 em uma indústria processadora de Guariroba indústria processadora de Guariroba

\begin{tabular}{lcccccc}
\hline Aspectos avaliados & \multicolumn{2}{c}{ Conforme } & \multicolumn{2}{c}{ Não conforme } & \multicolumn{2}{c}{ NA* } \\
& FA $^{1}$ & $\%$ & FA & $\%$ & FA & $\%$ \\
\hline Edificações e instalações & 18 & 78 & 3 & 13 & 2 & 9 \\
Equipamentos e utensílios & 6 & 100 & 0 & 0 & 0 & 0 \\
Produção/manipulação/venda & 3 & 75 & 1 & 25 & 0 & 0 \\
Matérias-primas e produtos expostos à venda & 4 & 100 & 0 & 0 & 0 & 0 \\
Fluxo de produção, manipulação, venda e controle de & & & & & \\
qualidade & 8 & 80 & 2 & 20 & 0 & 0 \\
Manual BPF & 1 & 100 & 0 & 0 & 0 & 0 \\
\hline
\end{tabular}

*Não se aplica; ${ }^{1}$ Frequência absoluta

Os aspectos "equipamento e utensílio", "matérias-primas" e produtos expostos à venda" e "existência de manual de BPF" apresentaram $100 \%$ de conformidade, demonstrando a preocupação da agroindústria com a produção de um alimento seguro. Embora os funcionários tenham recebido capacitação de BPF durante a realização do trabalho, é de fundamental importância que estes treinamentos se repitam, como forma de relembrar a importância que as 
BPFs representam e as normas básicas que devem ser seguidas. Seaman and Eves (2010)| verificaram que administradores de estabelecimentos produtores de alimentos estão cientes da responsabilidade em capacitar os colaboradores, mas comumente não têm suporte necessário para garantir que estes tenham práticas adequadas de manipulação de alimentos.

$\mathrm{Na}$ agroindústria avaliada, observou-se que o processo de implantação e manutenção das BPF é realizado pelo proprietário sem auxílio de entidades governamentais, portanto, caso haja incentivo por meio da aplicação de cursos de capacitação, pode trazer um impacto positivo sobre as conformidades, conforme relatado por Cruz (2007), que pesquisou sobre a qualidade e BPF em um contexto de agroindústrias rurais de pequeno porte de Santa Catarina e identificou que as realizações de cursos favoreceram o envolvimento dos agricultores e facilitaram a construção do conhecimento em boas práticas, higiene e legislação sanitária. Essas questões estão de acordo aos sugeridos por Toledo et al. (2000) em meados de (2000) que relataram que o setor agropecuário, não pode mais ser abordado de maneira não dissociada dos outros agentes responsáveis pelas atividades que garantem a produção, a transformação, a distribuição e o consumo de alimentos, deve-se investir em capacitação e garantia da qualidade.

Os resultados gerais, ou seja, a média geral de conformidade foi de $88,8 \%$; resultados superiores aos observados por Santos (2014) que verificou em unidades agroindústrias familiares localizadas em Brasília/DF conformidades de $77 \%$. Outro ponto que deve ser destacado é que em a avaliação das BPF em agroindústria familiar é incomum mediante pesquisa em periódicos de bases de dados em língua portuguesa. $\mathrm{O}$ fato demonstra uma carência de pesquisa no setor, intensificando a importância da presente avaliação, como norteadora de possíveis ações para agroindústria familiar. A agroindústria de processamento de guariroba analisada, apesar de ser familiar e de pequeno porte, apresentou condições positivas para realizar o processamento de alimentos para humanos. O grupo gestor é consciente da necessidade da adequação do estabelecimento à legislação, onde benefícios futuros serão obtidos pela otimização da produção e a garantia da inocuidade do produto final oferecido. O método utilizado para a implantação das BPFs foi prático e funcional, permitindo que as não conformidades fossem identificadas rapidamente e regularizadas de forma organizada e objetiva.

\section{Conclusão}

A implantação das BPFs na agroindústria familiar de processamento de guariroba foi executada com sucesso, atingindo os objetivos propostos, observando o quanto é complexa a implantação na íntegra das BPFs e que há necessidade de melhorias constantes, utilizandose ferramentas da qualidade.

\section{Referências Bibliográficas}

Anacleto, C. A. \& Paladini, E. P. 2014. Gestão estratégica da qualidade para empresas produtoras de alimentos orgânicos: diretrizes para a expansão do mercado consumidor. Navus-Revista de Gestão e Tecnologia, 5, 5164.

Andrade, A. C. S., Venturi, S. \& Paulilo, M. T. S. 1996. Efeito do tamanho das sementes de Euterpe edulis Mart. sobre a emergência e crescimento inicial. Revista Brasileira de Sementes, 18, 225-231.

Brasil, Ministério da Saúde. Agência Nacional de Vigilância Sanitária. Resolução RDC n ${ }^{\circ} 275$, 21 de Outubro de 2002. Dispõe sobre o Regulamento Técnico de Procedimentos Operacionais Padronizados aplicados aos Estabelecimentos Produtores/ Industrializadores de Alimentos e a Lista de Verificação de Boas Práticas de Fabricação em Estabelecimentos Produtores/ Industrializadores de Alimentos.

Brasil. Secretaria de Agricultura Familiar (MDA) - Programa Agroindústria. Recomendações Básicas para a Aplicação das Boas Práticas Agropecuárias e de Fabricação na Agricultura Familiar. Brasília: Embrapa Informação Tecnológica, 2006, 247p.

França, C. G., Del Grossi, M. E. \& Marques, V. P. M. 2009. El censo agropecuario 2006 y la agricultura familiar en Brasil. Brasília.

Jaime, N. G., Moura, C. J. \& Paula, Y. O. 2007. Aceitação do palmito de guariroba [Syagrus oleracea (Mart.) Becc.] em conservas sob diferentes ácidos orgânicos. Pesquisa Agropecuária Tropical, 37, 257-266.

Kamimura, A., Oliveira, A. \& Burani, G. F. 2010. A agricultura familiar no Brasil: um retrato do 
desequilíbrio regional. Interações, 11, 217223.

Santos, L. V. 2014. Avaliação das boas práticas de fabricação em agroindústrias do Distrito Federal (DF). Nutrição. Universidade de Brasília, Brasília.

Seaman, P. \& Eves, A. 2010. Perceptions of hygiene training amongst food handlers, managers and training providers-A qualitative study. Food Control, 21, 1037-1041.

Silva, L. A. \& Correia, A. F. K. 2011. Manual de boas práticas de fabricação para indústria fracionadora de alimentos. Revista de Ciência \& Tecnologia, 16, 39-57.
Toledo, J. C., Batalha, M. O. \& Amaral, D. C. 2000. Qualidade na indústria agroalimentar: situação atual e perspectivas. Revista de Administração de Empresas, 40, 90-101.

\section{Article History:}

Received 10 November 2016

Accepted 08 January 2016

Available on line 13 February 2017

License information: This is an open-access article distributed under the terms of the Creative Commons Attribution License 4.0, which permits unrestricted use, distribution, and reproduction in any medium, provided the original work is properly cited. 